Diabetologia (1994) 37: 713-720

\title{
Pharmacokinetics, pharmacodynamics and glucose counterregulation following subcutaneous injection of the monomeric insulin analogue [Lys(B28),Pro(B29)] in IDDM
}

\author{
E. Torlone, C. Fanelli, A. M. Rambotti, G. Kassi, F. Modarelli, A. Di Vincenzo, L. Epifano, M. Ciofetta, \\ S.Pampanelli, P. Brunetti, G. B. Bolli \\ Dipartimento di Medicina Interna e Scienze Endocrine e Metaboliche, Università di Perugia, Perugia, Italy
}

\begin{abstract}
Summary The aim of these studies was to compare the pharmacokinetics, pharmacodynamics, counterregulatory hormone and symptom responses, as well as cognitive function during hypoglycaemia induced by s.c. injection of $0.15 \mathrm{IU} / \mathrm{kg}$ of regular human insulin (HI) and the monomeric insulin analogue [Lys(B28), Pro (B29)] (MI) in insulin-dependent-diabetic (IDDM) subjects. In these studies glucose was infused whenever needed to prevent decreases in plasma glucose below $3 \mathrm{mmol} / \mathrm{l}$. After MI, plasma insulin increased earlier to a peak ( $60 \mathrm{vs} 90 \mathrm{~min}$ ) which was greater than after HI ( $294 \pm 24$ vs $255 \pm 24 \mathrm{pmol} / \mathrm{l})$, and plasma glucose decreased earlier to a $3 \mathrm{mmol} / \mathrm{l}$ plateau (60 vs $120 \mathrm{~min})(p<0.05)$. The amount of glucose infused to prevent plasma glucose falling below $3 \mathrm{mmol} / \mathrm{l}$ was - three times greater after MI than HI $(293 \pm 26$ vs $\left.90 \pm 25 \mu \mathrm{mol} \cdot \mathrm{kg}^{-1} \cdot 60-375 \mathrm{~min}^{-1}, p<0.05\right)$. After MI, hepatic glucose production was more suppressed $\left(0.7 \pm 1\right.$ vs $\left.5.9 \pm 0.54 \mu \mathrm{mol} \cdot \mathrm{kg}^{-1} \cdot \mathrm{min}^{-1}\right)$ and glucose utilization was less suppressed than after HI $\left(11.6 \pm 0.65\right.$ vs $\left.9.1 \pm 0.11 \mu \mathrm{mol} \cdot \mathrm{kg}^{-1} \cdot \mathrm{min}^{-1}\right)(p<0.05)$. Similarly, plasma NEFA, glycerol, and $\beta$-OH-butyrate
\end{abstract}

were more suppressed after MI than HI $(p<0.05)$, whereas plasma lactate increased only after MI, but not after HI. Responses of counterregulatory hormones, symptoms and deterioration in cognitive function during plasma glucose plateau of $3 \mathrm{mmol} / \mathrm{l}$ were superimposable after MI and HI ( $p=$ NS). Post-hypoglycaemia hyperglycaemia was greater after MI than HI (at $480 \mathrm{~min} 12.1 \pm 1$ vs $11 \pm 1 \mathrm{mmol} / \mathrm{l}$ ) because of greater hepatic glucose production during insulin. waning which occurred at least 135 min earlier with MI as compared to HI $(p<0.05)$. It is concluded that counterregulatory hormones, symptoms and deterioration in cognitive function during hypoglycaemia respond similarly after MI and HI. The biological effect of MI appears greater than that of HI for at least $4 \mathrm{~h}$ after the s.c. injection and appears as a good candidate for achieving optimal post-prandial glucose control in IDDM. [Diabetologia (1994) 37: 713-720]

Key words Hypoglycaemia, counterregulation, insulin analogues, catecholamines, hypoglycaemic symptoms, monomeric insulin.
Received: 6 December 1993

and in revised form: 9 February 1994

Corresponding author: Professor G.B.Bolli, Dipartimento di Medicina Interna e Scienze Endocrine e Metaboliche, Via E.Dal Pozzo, I-06126 Perugia, Italy

Abbreviations: HI, Human insulin; MI, monomeric insulin; NE$\mathrm{FA}$, non-esterified fatty acid; $\mathrm{HGO}$, hepatic glucose production rate; $\beta$-OH-butyrate, $\beta$-hydroxy-butyrate; IDDM, insulin-dependent diabetes mellitus; NIDDM, non-insulin-dependent diabetes mellitus.
There are at least three good reasons why prandial insulin administration in IDDM subjects fails to reproduce the plasma glucose homeostasis of non-diabetic subjects [1]. First, the peripheral, rather than portal means of insulin delivery. This causes underinsulinization of the liver and an excessive release of endogenous glucose into the bloodstream, a problem which may be overcome at present only at the expense of peripheral hyperinsulinaemia $[1,2]$. Second, the subcutaneous (s.c.) rather than intravenous (i.v.) route of insulin delivery. Because absorption of insulin by the s.c. tissue is a slow process [3], the rate of increase in plasma insulin is slower, the peak smaller, and the post-peak plasma 
insulin concentrations greater, in diabetic subjects injected with s. c. insulin (because of the ongoing absorption of insulin by the s.c. depot) compared to nondiabetic subjects secreting insulin in response to a meal directly into the portal vein $[1,4]$. The initially low plasma insulin bioavailability causes early post prandial hyperglycaemia [4], whereas the inappropriate hyperinsulinaemia late after s. c. insulin may frequently cause hypoglycaemia in IDDM [4]. Third, the estimate of the prandial insulin dose in IDDM remains empirical. Understandably, under- or over-estimation of the insulin dose easily results in post-prandial hyper- or hypoglycaemia independently of the two previous factors.

Recently, relevant advances have been made in producing insulin formulations with faster s.c. absorption as compared to human insulin (HI), with the so-called monomeric insulin (MI) analogues [5,6]. Although a number of MI analogues have been produced [6], only a few are candidates for the prandial insulin needs in subjects with either IDDM or NIDDM. Of these, [Lys(B28),Pro(B29)] [7] has proven to result in the most physiological plasma insulin pharmacokinetics and pharmacodynamics when injected s.c., as compared to HI $[8,9]$. [Lys(B28),Pro(B29)] and HI bind IGF-I receptors and stimulate cell growth to a similar extent [10].

Several studies have assessed the biological effects of analogue[Lys(B28),Pro(B29)] in euglycaemic clamp experiments in non-diabetic subjects $[8,9,11,12]$, as well as during physical exercise [13], and clinical trials in IDDM and NIDDM [14, 15]. However, so far no study has tested the counterregulatory hormone, or the symptom responses and cognitive function during hypoglycaemia induced by [Lys(B28),Pro(B29)].

The present series of studies was undertaken, first, to compare the time-course of onset of hypoglycaemia after s.c. injection of the MI analogue [Lys(B28), Pro(B29)] and HI, and to define the mechanisms. Second, to compare the counterregulatory hormone and symptom responses to hypoglycaemia, and, third, the development of post-hypoglycaemic hyperglycaemia after s. c. injection of MI as compared to HI.

\section{Materials and methods}

Subjects. Institutional Review Board approval was obtained for these studies. Informed consent was given by eight subjects with IDDM (Table 1). At the time of study, all the subjects were free of any detectable diabetic complications. They had no autonomic neuropathy, as judged on the basis of a standard battery of cardiovascular tests [16]. They had no other disease apart from diabetes, and were not taking any drugs other than insulin. Their insulin antibody titre [2] was $7 \pm 1 \%$.

Study design. The subjects were studied on two occasions, at 23 week intervals. On both occasions, the subjects were admitted to the Clinical Research Centre of the Department of Internal Medicine, Endocrinology and Metabolism, University of Perugia, the night prior to the study between $21.00-21.30$ hours. Long-acting insulin was withdrawn for $48 \mathrm{~h}$ prior to the study and
Table 1. Clinical characteristics of the subjects studied

\begin{tabular}{ll}
\hline Number of subjects & 8 \\
Male/Female & $4 / 4$ \\
Age (years) & $30 \pm 3$ \\
Body mass index $\left(\mathrm{kg} / \mathrm{m}^{2}\right)$ & $21 \pm 1$ \\
Duration of diabetes (years) & $16 \pm 2$ \\
Number of & 4 (regular insulin at each meal, \\
injections/day & NPH insulin at bed-time) \\
HbA $_{1 \mathrm{c}}(\%)^{\mathrm{a}}$ & $6.56 \pm 0.4$ \\
\hline
\end{tabular}

a Values in non-diabetic subjects: $3.8-5.5 \%$

was replaced by injections of regular insulin at each meal, at bedtime, and at 03.00 hours. On the night prior to the studies, the subjects were maintained in normoglycaemia $(\sim 5 \mathrm{mmol} / \mathrm{l})$ by an i. v. infusion of insulin into a superficial vein of the left arm above the elbow, as previously described [17]. This venous access was also used the following morning for infusion of "hot" (tritiated) and "cold" glucose. All subjects were studied in the fasting state, approximately 12-14 hafter the last meal, and remained fasted until the end of the studies. At 07.00 hours, a primed $(20 \mu \mathrm{Ci})$-continuous $(0.2 \mu \mathrm{Ci} / \mathrm{min})$ infusion of $\mathrm{d}-\left(3{ }^{3} \mathrm{H}\right)$-glucose (New England $\mathrm{Nu}$ clear, Boston, Mass., USA) was initiated and maintained throughout the studies by means of a syringe pump (Harvard Apparatus Co., Inc., The Ealing Co., South Natik, Mass., USA) for isotopic determination of glucose fluxes. Between 07.00 and 07.30 hours, a hand vein in the left arm was retrogradely cannulated and maintained in a plexiglass thermoregulated box $\left(\sim 65^{\circ} \mathrm{C}\right)$ for sampling of arterialized-venous blood [18]. Both the forearm and hand venous lines were kept patent by infusion of $0.9 \% \mathrm{NaCl}, 0.5 \mathrm{ml} / \mathrm{min}$, by means of two separate peristaltic pumps (VM $8000 \mathrm{M}$; Vial Medical, St-Martin-Le-Vinoux, Grenoble, France). At 09.00 hours, 0.15 IU/kg of HI(Humulin R U-100; Eli Lilly \& Co., Indianapolis, Ind., USA) (HI) or, on the other occasion, of the MI analogue [Lys(B28),Pro(B29) U-100, Eli Lilly \& Co.], were s. c. injected. The sequence of the studies (single-blind, patient) was varied at random. To inject insulin as reproducibly as possible, the injection was always given by the same investigator (ET) with a 28-gauge, 1-ml (U-100) syringe (Becton Dickinson, Carlo Erba, Milan, Italy) with a fixed needle. Insulin was injected into the anterior abdominal wall, $4 \mathrm{~cm}$ lateral to the umbilicus, inclined at $45^{\circ}$, and with a penetration of approximately 4-5 $\mathrm{mm}$. Care was taken to standardize the speed of injection and removal of the syringe as much as possible. Since one unit of MI is defined in exactly the same way as HI (by HPLC on a molecular weight basis), and since both MI and HI have identical molecular composition and molecular weight, in these studies the same amount of MI and HI was given on molar basis. After the s.c.insulin injection, thei.v.insulin infusion was tapered ( $75 \%$ of the mean insulin requirements between $08.30-09.00$ hours was continued until 09.10 hours, $50 \%$ until 09.20 hours, and $25 \%$ until 09.30 hours) and then stopped at 09.30 hours. Glucose ( $20 \%$ solution), was infused by means of a separate Harvard pump when required to prevent the plasma glucose concentration falling below $3.0 \mathrm{mmol} / 1$. Arterialized-venous blood samples were drawn every $30 \mathrm{~min}$ for determination of plasma free insulin, growth hormone, glucagon, cortisol, adrenaline and noradrenaline and intermediary metabolites. A semiquantitative symptom questionnaire was completed every $15 \mathrm{~min}$. Subjects scored from 0 (none) to 5 (severe) for each of the following symptoms: dizziness, tingling, blurred vision, difficulty in thinking, faintness, anxiety, palpitations, hunger, sweating, irritability, or tremor. In accordance with previous classifications $[19,20]$, the 
Table 2. Insulin infusion rates $\left(\mathrm{mU} \cdot \mathrm{kg}^{-1} \cdot \mathrm{min}^{-1}\right)$ between -30 and $0 \mathrm{~min}$ ( $0 \mathrm{~min}$, baseline) and over the $30 \mathrm{~min}$ following s.c. injection of either monomeric insulin analogue (MI) or human insulin (HI) in the diabetic subjects

\begin{tabular}{lcccr}
\hline $\begin{array}{l}\text { Time of } \\
\text { study (min) }\end{array}$ & 0 & 10 & 20 & \multicolumn{1}{c}{30} \\
\hline MI Study & $0.18 \pm 0.01$ & $0.14 \pm 0.01$ & $0.09 \pm 0.01$ & $0.045 \pm 0.01$ \\
HI Study & $0.20 \pm 0.02$ & $0.15 \pm 0.01$ & $0.10 \pm 0.01$ & $0.05 \pm 0.01$ \\
\hline
\end{tabular}
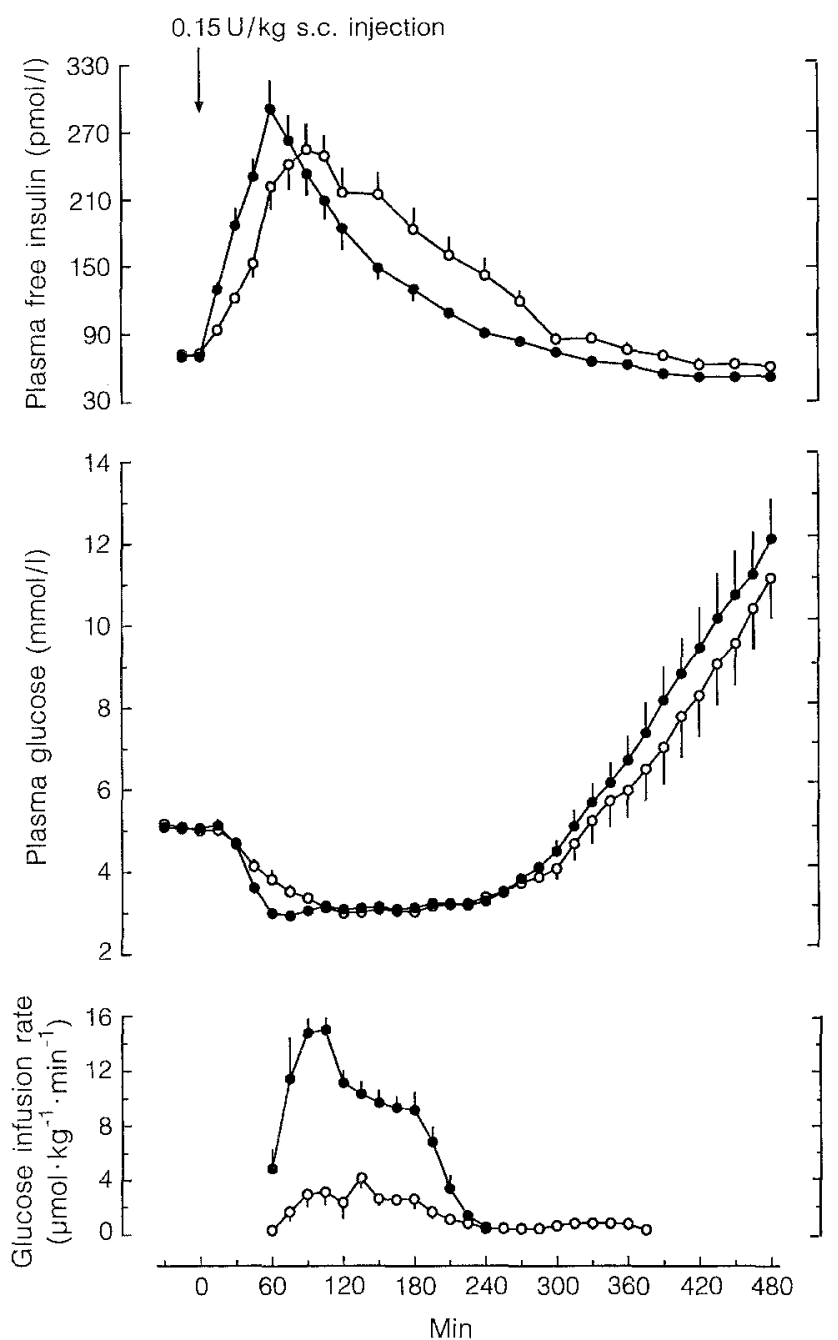

Fig. 1. Plasma insulin and glucose concentrations, and rates of glucose infusion required to prevent decreases in plasma glucose below $3 \mathrm{mmol} / \mathrm{l}$ after s.c. injection of human insulin $O$, or the rapid-acting, monomeric insulin analogue - [Lys(B28),Pro (B29)] in eight subjects with IDDM. Intravenous insulin was continued from 0 through $30 \mathrm{~min}$ (Table 2). Results are mean \pm SEM

first five symptoms were considered neuroglycopenic and the last six, autonomic. The sum of each of these constituted the symptom score. In addition, at baseline and at 60-min intervals the following standard cognitive tests were compiled: trail-making part B, verbal fluency, interference subtest from the Stroop test, simple and choice visual reaction time, word and colour subtest from the Stroop test, digit vigilance test, trail-making part A, verbal memory test and forward and backward digit span, as previously described [19]. The evening before the study, subjects extensively practiced each test. For the actual study, six alternate forms were prepared. The diabetic subjects and the person who recorded the symptoms were unaware of the experimental condition.

Analytical methods. Plasma glucose was measured using a Beckman Glucose Analyzer (Beckman Instruments, Palo Alto, Calif., USA). Plasma insulin, growth hormone, cortisol, adrenaline, noradrenaline [21], and $\left(3-{ }^{3} \mathrm{H}\right)$-glucose radioactivity [22] were measured as previously described. To remove antibodybound insulin, plasma was mixed with an equal volume of $30 \%$ polyethylene glycol immediately after blood collection [17]. Plasma glucagon was measured by radioimmunoassay using a commercially available kit (ICN Biomedical, Inc., Costa Mesa, Calif., USA). Plasma insulin was measured using a commercially available kit (Incstar Co., Stillwater, Minn., USA). Recovery was $98 \pm 1 \%$ at insulin concentration of $24 \mathrm{pmol} / 1,96 \pm 2 \%$ at $300 \mathrm{pmol} / \mathrm{l}$, and $91 \pm 2 \%$ at $600 \mathrm{pmol} / \mathrm{l}$. Plasma NEFA were measured by an enzymatic colorimetric method (Wako NEFA C test kit; Wako Chemicals GmbH, Neuss, Germany), and $\beta$-OHbutyrate, glycerol, alanine by a previously described method [23]. $\mathrm{HbA}_{1 \mathrm{c}}$ was determined by an HPLC method (range in nondiabetic subjects $3.8-5.5 \%$ ).

Calculations and statistical methods. Rates of glucose appearance (production) and disappearance (utilization) were calculated using the non-steady-state equations of De Bodo et al. [24], and were smoothed according to the method of Miles et al. [25]. The infusion of cold glucose, if any, was integrated over 30 -min intervals and subtracted from the total rate of glucose appearance to obtain the endogenous (hepatic) HGO. Because of differences in units of treatment, results of cognitive tests were transformed to $\mathrm{z}$-scores (individual values minus mean divided by standard deviation) [26] to permit their summation to obtain one unitless value for evaluation [19]. Data are given as means \pm SEM, and the statistical significance was evaluated using analysis of variance corrected for repeated measures [26]. A commercially available software package (CSS, Stasoft, Tulsa, Okla., USA) was used for statistical analysis.

\section{Results}

Insulin infusion rates and plasma glucose concentrations at baseline (Table 2). The i.v. insulin requirements to maintain euglycaemia at baseline were superimposable in the two studies. The rates of $i$. v. insulin infusion over the $30 \mathrm{~min}$ following the s.c. injection of either MI or HI were also superimposable.

Plasma insulin and glucose concentrations and rates of glucose infusion (Fig. 1). After the s.c. MI injection, plasma insulin concentration increased to an earlier $(60$ vs $90 \mathrm{~min})$ and greater $(294 \pm 24$ vs $255 \pm 24 \mathrm{pmol} / \mathrm{l})$ $(p<0.05)$ peak than after HI. However, after $105 \mathrm{~min}$, the plasma insulin concentration was greater after $\mathrm{HI}$ than after MI (114 \pm 14 vs $86 \pm 13 \mathrm{pmol} / \mathrm{l}$, mean of the $120-480$ values, $p<0.05)$. The area under the plasma insulin curves after HI was slightly greater than after MI $\left(65.4 \pm 3.5 \mathrm{vs} 57.6 \pm 2.6 \mathrm{nmol} \cdot 1^{-1} \cdot 480 \mathrm{~min}^{-1}, p<0.05\right)$.

Plasma glucose concentration decreased more rapidly after $\mathrm{MI}$ as compared to $\mathrm{HI}$. When glucose was infused to prevent plasma glucose concentration falling below $3 \mathrm{mmol} / \mathrm{l}$, the plasma glucose concentration pla- 

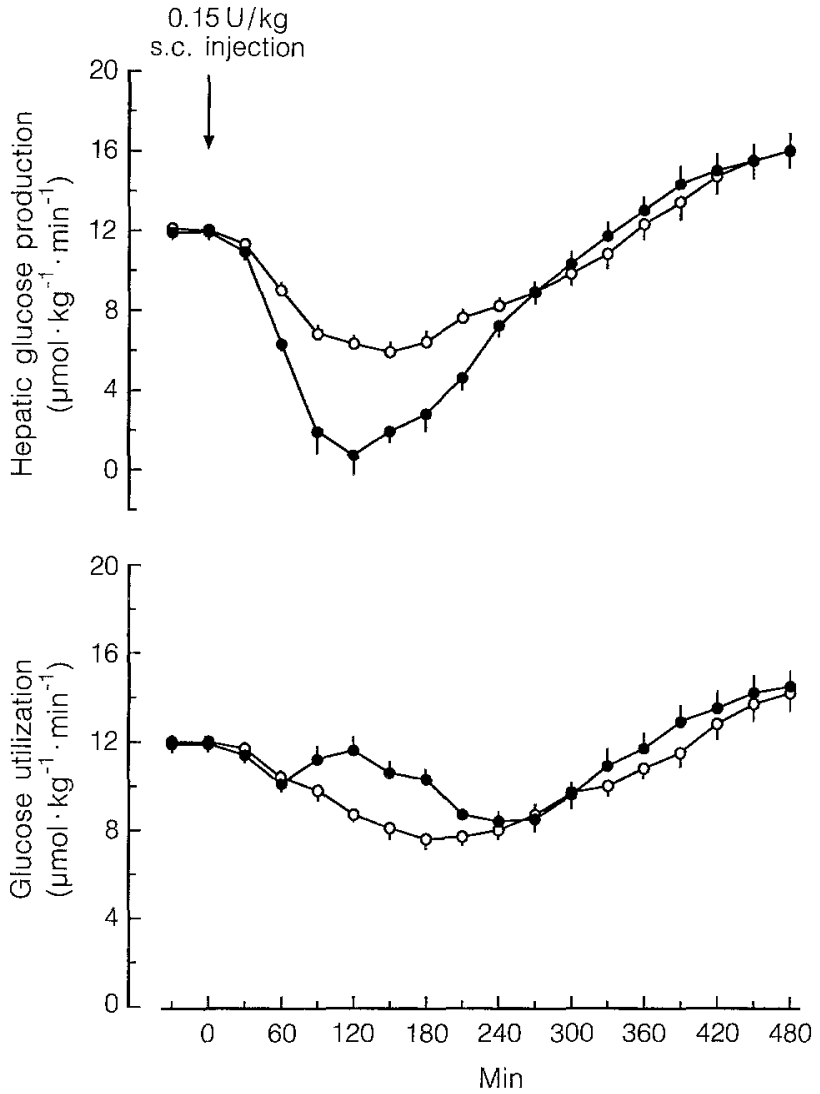

Fig. 2. Rates of hepatic (endogenous) glucose production and glucose utilization after s.c. injection of human insulin $O$, or the rapid-acting, monomeric insulin analogue $-[$ Lys(B28), Pro(B29)] in eight subjects with IDDM. Note that i.v. insulin was continued from 0 through $30 \mathrm{~min}$ (Table 2), and i.v. glucose was infused whenever needed to prevent decreases in plasma glucose below $3 \mathrm{mmol} / \mathrm{l}$ (Fig. 1). Results are mean \pm SEM teaued at similar values after MI and HI up to $240 \mathrm{~min}$. Thereafter, plasma glucose concentration increased on both occasions, but the increase at $480 \mathrm{~min}$ was slightly greater after MI $(12.1 \pm 1 \mathrm{mmol} / \mathrm{l})$ than after $\mathrm{HI}$ $(11 \pm 1 \mathrm{mmol} / \mathrm{l})(p<0.05)$.

In both studies glucose was required to prevent decreases in plasma glucose below $3 \mathrm{mmol} / \mathrm{l}$. However, the amount of glucose infused between 60-375 min was approximately 3 times greater after MI than HI (areas under curves $293 \pm 26$ vs $90 \pm 25 \mu \mathrm{mol} \cdot \mathrm{kg}^{-1} \cdot 60$ $\left.375 \min ^{-1}, p<0.05\right)$.

Rates of HGO and glucose utilization (Fig. 2). After the s.c. injection, the rates of $\mathrm{HGO}$ initially decreased to a lower and earlier nadir in the MI $\left(0.7 \pm 1 \mu \mathrm{mol} \cdot \mathrm{kg}^{-1}\right.$ - $\mathrm{min}^{-1}$ at $120 \mathrm{~min}$ ) as compared to the HI study $\left(5.9 \pm 0.54 \mu \mathrm{mol} \cdot \mathrm{kg}^{-1} \cdot \mathrm{min}^{-1}\right.$ at $\left.150 \mathrm{~min}\right)$. Thereafter, $\mathrm{HGO}$ increased on both occasions and rebounded above baseline values after $330 \mathrm{~min}$. After $210 \mathrm{~min}$, HGO was superimposable in the two studies.

Glucose utilization did not increase in either study until plasma glucose concentration increased above baseline values. However, in the MI study, glucose utilization was less suppressed than in the HI study between $90-180 \min (p<0.05)$.

\section{Plasma counterregulatory hormones (Fig. 3)}

Plasma glucagon did not increase in response to hypoglycaemia. Plasma adrenaline, noradrenaline, growth hormone and cortisol increased to similar peak values in the MI and HI studies ( $p=\mathrm{NS}$ ), but the peak response occurred earlier in the MI study (adrenaline 120 vs $180 \mathrm{~min}$; noradrenaline 150 vs $210 \mathrm{~min}$; growth hormone 90 vs $120 \mathrm{~min}$; cortisol 90 vs $120 \mathrm{~min}$, MI and HI studies, respectively).

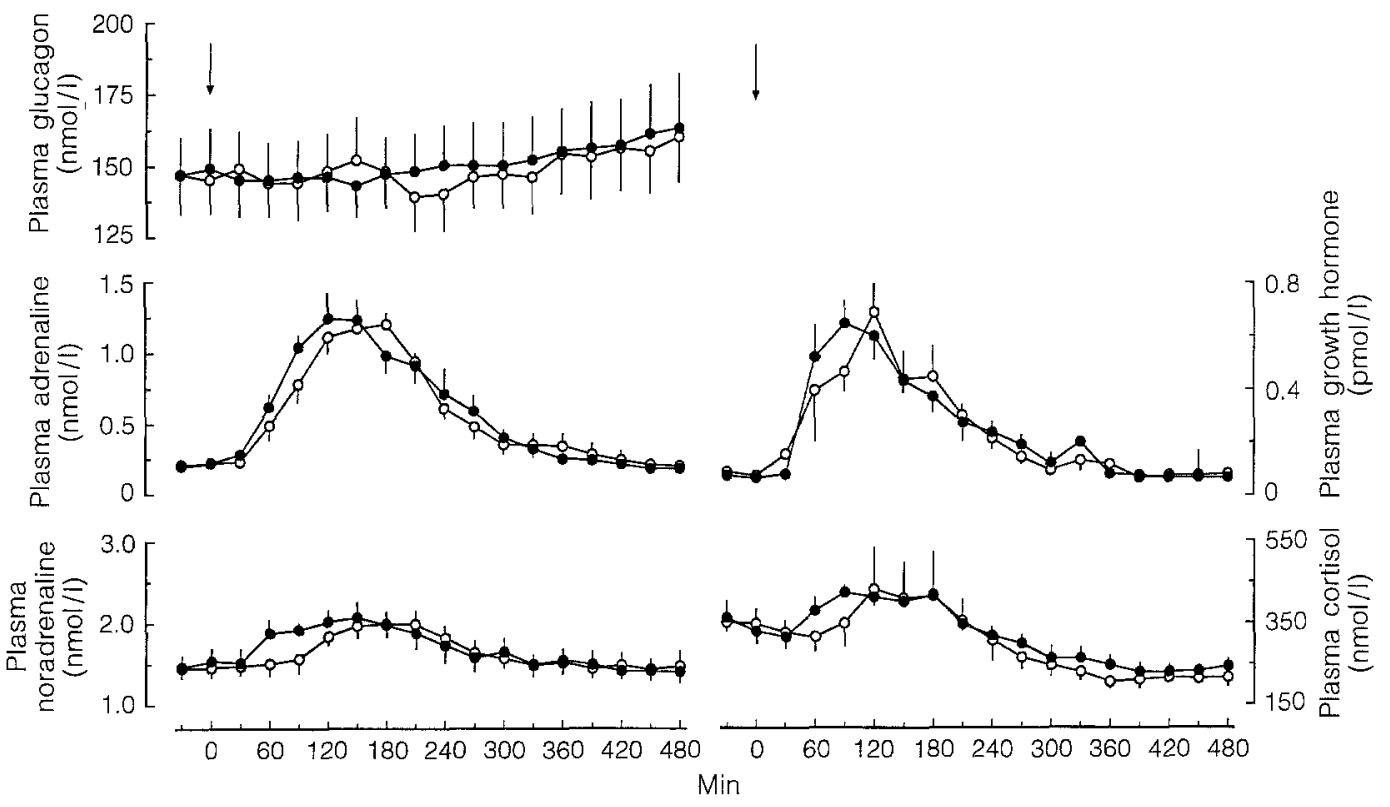

Fig.3. Plasma counterregulatory hormone responses to hypoglycaemia induced by s.c. injection of human insulin $\mathrm{O}$, or the rapid-acting, monomeric insulin analogue $\bullet$ [Lys(B28), Pro(B29)] in eight subjects with IDDM. Note that i.v. glucose was infused whenever needed to prevent decreases in plasma glucose below $3 \mathrm{mmol} / 1$ (Fig. 1). Results are mean \pm SEM 

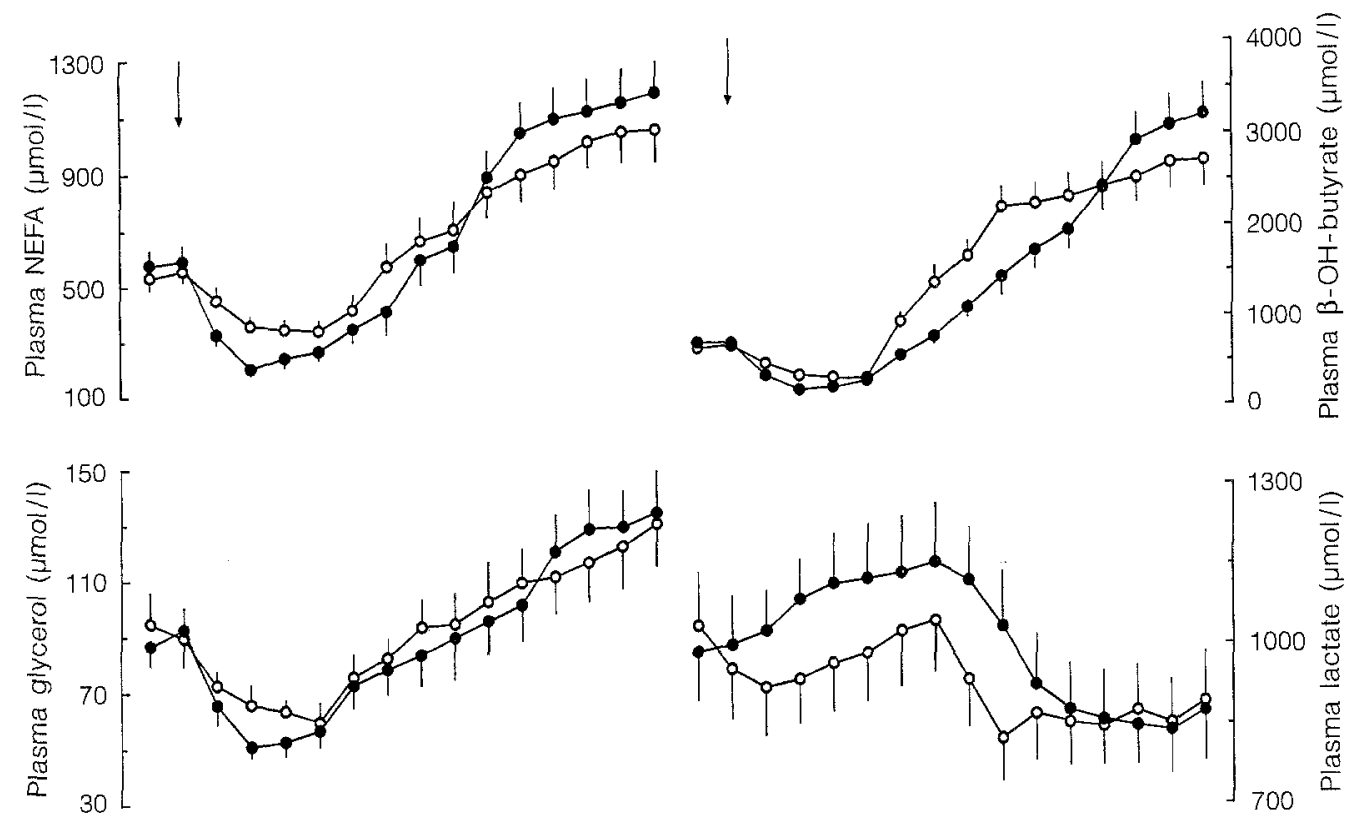

Fig.4. Plasma substrate concentrations during and after hypoglycaemia induced by s. c. injection of human insulin $\bigcirc$, or the rapid-acting, monomeric insulin analogue - [Lys(B28),Pro(B29)] in. eight subjects with IDDM. Note that i.v. glucose was infused whenever needed to prevent decreases in plasma glucose below $3 \mathrm{mmol} / \mathrm{l}$ (Fig. 1). Results are mean \pm SEM

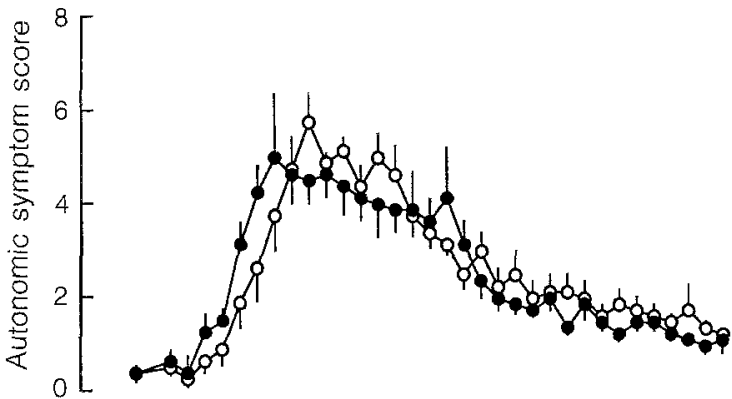

Plasma intermediary metabolite concentrations (Fig. 4)

Plasma NEFA and glycerol concentrations were more suppressed after the s.c. injection of MI than HI up to 210 min, whereas $\beta$-OH-butyrate was more suppressed up to $300 \mathrm{~min}$. Subsequently, plasma NEFA and glycerol concentrations were slightly, but not significantly greater after $\mathrm{MI}$ than $\mathrm{HI}$. $\beta$-OH-butyrate was greater in the MI than the HI studyafter $360 \min (p<0.05)$. Plasma lactate did not change after the s. c. HI injection, whereas it increased between 60-270 min after the MI injection.

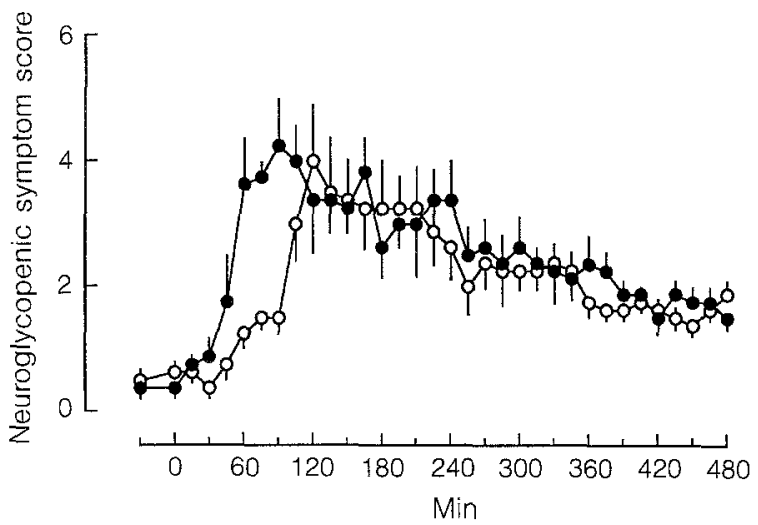

Fig.5. Score of autonomic and neuroglycopenic symptoms during hypoglycaemia induced by s.c. injection of human insulin $O$, or the rapid-acting, monomeric insulin analogue - [Lys(B28), Pro(B29)] in eight subjects with IDDM. Note that i.v. glucose was infused whenever needed to prevent decreases in plasma glucose below $3 \mathrm{mmol} / \mathrm{l}$ (Fig. 1). Results are mean \pm SEM

Scores of symptom responses to hypoglycaemia (Fig. 5)

The peaks of the scores of autonomic and neuroglycopenic symptoms in the MI and HI studies were similar ( $p=\mathrm{NS})$. However, in the MI study, the peaks of scores of autonomic and neuroglycopenic symptoms occurred earlier (at $90 \mathrm{~min}$ ) than in the HI study (at $120 \mathrm{~min}$ ).

\section{Cognitive function (Table 3)}

Deterioration of cognitive function during hypoglycaemia was similar after $\mathrm{HI}$ and $\mathrm{MI}$, but it occurred earlier after MI.

\section{Discussion}

The present series of studies was undertaken, first, to compare the time-course of onset of hypoglycaemia after s.c. injection of the MI analogue [Lys(B28), 
Table 3. Cognitive function (sum of $Z$ scores of psychomotor tests) after s.c. injection of human insulin (HI) or monomeric insulin [Lys(B28),Pro(29)] (MI) in eight subjects with IDDM. A negative Z score represents deterioration, a positive Z score, improvement in cognitive funtion

\begin{tabular}{lcccccccc}
\hline Time $(\min )$ & 0 & 60 & 120 & 180 & 240 & 300 & 360 & 420 \\
\hline HI & 0.1 & -0.4 & 1.1 & $-6.5^{\mathrm{a}}$ & $-2.7^{\mathrm{a}}$ & -1.2 & -0.6 & -1.1 \\
& \pm 0.01 & \pm 0.01 & \pm 0.2 & \pm 0.5 & \pm 0.3 & \pm 0.2 & \pm 0.1 & \pm 0.2 \\
MI & 0.2 & -2.7 & $-4.4^{\mathrm{a}}$ & $-6.8^{\mathrm{a}}$ & $-3.1^{\mathrm{a}}$ & -1.6 & -0.2 & -0.4 \\
& \pm 0.01 & \pm 0.25 & \pm 0.21 & \pm 0.45 & \pm 0.2 & \pm 0.3 & \pm 0.2 & \pm 0.35 \\
\hline
\end{tabular}

${ }^{\mathrm{a}} p<0.05$ vs basal

Pro(B29)] and HI. Second, to compare the counterregulatory hormone and symptom responses, and, third, the development of post-hypoglycaemic hyperglycaemia after s. c. injection of MI as compared to HI. Our results in response to these questions indicate the following.

First, s.c. injection of prandial therapeutic doses of MI in IDDM results in an earlier hypoglycaemia as compared to HI. Regarding the mechanisms, MI lowered plasma glucose predominantly by suppressing HGO and only marginally by increasing glucose utilization, whereas HI only suppressed HGO. In fact, in the present studies glucose utilization paradoxically did not increase (HI), or increased transiently to only a limited extent (MI), as previously reported [2], because of the mass action effect of low plasma glucose [27] and insulin resistance of IDDM [28].

Second, the counterregulatory and symptom (both autonomic and neuroglycopenic) responses, as well as deterioration in cognitive function during hypoglycaemia induced by s.c. injection of $\mathrm{MI}$ and $\mathrm{HI}$ insulin were superimposable.

Third, post-hypoglycaemic hyperglycaemia was greater after the s. c. injection of MI as compared to HI. However, plasma glucose concentration at $480 \mathrm{~min}$ was only approximately $1 \mathrm{mmol} / \mathrm{l}$ greater after $\mathrm{MI}$ as compared to HI insulin. Thus, rebound hyperglycaemia following hypoglycaemia [29] induced by MI is not greatly exaggerated as compared to $\mathrm{HI}$.

An important finding in the present studies was not only the earlier but also the greater hypoglycaemic effect of MI as compared to HI, as indicated by the greater rate of spontaneous plasma glucose fall, and the greater glucose infusion rate needed to prevent a decrease in plasma glucose below $3 \mathrm{mmol} /$ lover the initial $4 \mathrm{~h}$ following s.c. injection of the two insulin preparations. Although the design of the present experiments in which hyperglycaemia followed hypoglycaemia, does not allow one to calculate the duration of action of $\mathrm{MI}$ as compared to HI, it is nevertheless clear that waning of insulin effect occurred earlier with the former as compared to the latter insulin preparation. In fact, glucose had to be infused up to $375 \mathrm{~min}$ following s.c. injection of $\mathrm{HI}$, whereas it was no longer needed after $240 \mathrm{~min}$ in the MI experiments. Thus, it can be estimated that the duration of action of MI is at least shorter 135 min than HI. However, it is likely that this is an underestimate, because post-hypoglycaemic hyperglycaemia developed faster after MI than HI.

The results of the present studies of an earlier and greater hypoglycaemic effect, as well as shorter duration of action of MI as compared to HI in IDDM, are in agreement with previous studies in normal, nondiabetic subjects, studied with the euglycaemic glucose clamp technique $[8,9,11,12]$, as well as in subjects with IDDM during exercise soon after s.c. injection [13]. However, in the present studies the overall biological effect of MI was about 3 times greater as compared to $\mathrm{HI}$, as shown by the amount of glucose infused during the entire experiment. Previous studies in normal, nondiabetic subjects, $[8,11,12]$ indicated that the biological effect of MI and HI was identical, if one considers the area under the curve of glucose infused in the euglycaemic glucose clamp experiments over 12-14 h. Clearly, the design of the present experiments does not allow a direct comparison between the present studies in hypoglycaemia in IDDM, and previous studies in euglycaemia in non-diabetic volunteers. However, the greater hypoglycaemic effect of MI as compared to $\mathrm{HI}$ for at least $3-3 \frac{1}{2}$ h observed in the present studies, is in agreement with the more profound hypoglycaemic effect reported by Tuominen et al. [13] during exercise soon after s. c. injection of MI as compared to HI.

In the present studies, the greater hypoglycaemic effect of MI as compared to HI was due to greater suppression of HGO and slightly stimulated glucose utilization. After MI, also suppression of NEFA, glycerol, $\beta$-OH-butyrate, and increase in lactate were greater than after HI. Because plasma glucose and counterregulatory hormone concentrations were superimposable in the two experiments, our interpretation was that these effects were due to the earlier plasma insulin bioavailability following MI as compared to $\mathrm{HI}$.

In the present studies, development of greater posthypoglycaemic hyperglycaemia after MI as compared to HI was the consequence of lower plasma insulin concentration late after s.c. injection of the former as compared to the latter insulin preparation. This is indicated by the superimposable plasma glucose counterregulatory hormone concentrations in the two experiments, as well as by the inverse correlation between the plasma glucose and insulin differences after $300 \mathrm{~min}$ in the $\mathrm{MI}$ and $\mathrm{HI}$ experiments $(r=-0.71, p<0.005)$. This confirms the key role of prevailing plasma insulin in the pa- 
thogenesis of post-hypoglycaemic hyperglycaemia [29, 30]. Notably, late after s.c. injection, hypoglycaemiaactivated counterregulation and insulin deficiency resulted in a greater rebound of lipolysis and ketogenesis as compared to glucose production and plasma glucose concentration. This effect was more pronounced with MI than HI.

The results of the present studies may be relevant to the use of MI prior to a meal in IDDM. First of all, when transferring a subject from $\mathrm{HI}$ to MI, not only the time interval between injection and meal should be reduced to $0-10 \mathrm{~min}$ [14], but also reduction of the dose should be considered to prevent early post-prandial hypoglycaemia, especially in subjects with pre-prandial nearnormoglycaemia. Second, should post-prandial hypoglycaemia occur, it is likely that a larger dose of glucose, compared to HI-induced hypoglycaemia, necessary for recovery of hypoglycaemia. However, third, because the present studies indicate that $4 \mathrm{~h}$ after s. c. injection of MI, diabetic patients are less hyperinsulinaemic than after HI, if intake of carbohydrate to correct hypoglycaemia is excessive, exaggerated post-hypoglycaemic hyperglycaemia might easily occur. Clearly, the success of the future use of MI, as compared to HI, is dependent upon the ability to prevent hypoglycaemia early after s.c. injection, as well as hypoinsulinaemia 4-5 h later. The last goal should be accomplished by multiple s.c. injections of MI at intervals no more than $5 \mathrm{~h}$ throughout the day. Alternatively, it is likely that about $20 \%$ of the total prandial insulin dose should be given as intermediate-acting insulin, the remaining $80 \%$ being MI, to prevent hypoinsulinaemia prior to the subsequent meal, in particular the evening meal. In fact, this is a frequent problem for subjects with IDDM living in Southern European countries.

The classic experiments of Dimitriadis and Gerich [4] demonstrated the critical importance of early plasma insulin bioavailability for physiological meal disposition, as well as the need for low plasma insulin concentrations late after s.c. insulin injection to prevent late post-prandial hypoglycaemia in IDDM. Previous studies $[8,9,12]$ and the present study indicate that s.c. injection of MI results in more physiological pharmacokinetics as compared to HI because of the faster s. c. absorption, the earlier and greater plasma insulin peak, and the more rapid post-peak decrease. Thus, it is presently hypothesized that s.c. injection of MI prior to a meal should result in better post-prandial glucose control as compared to HI in IDDM. However, because of the critical importance of loss of early phase insulin secretion in the pathogenesis of post-prandial hyperglycaemia in NIDDM [31], it is possible that MI results in better postprandial glucose control also in NIDDM. In a preliminary report on multicentre, randomized clinical trials in insulin-treated subjects with IDDM and NIDDM, both fasting as well as post-prandial blood glucose concentrations and $\% \mathrm{HbA}_{1 \mathrm{c}}$ were lower in the MI-treated as compared to HI-treated group [32].
Acknowledgements. This work was supported by grant 93.00352.PF40 for the C.N.R. finalized project on aging, and by the Juvenile Diabetes Foundation grant 193108. The dedicated editorial help of Ms. P. Boyce, the superb technical assistance of G. Cipiciani, and the friendly support from the IDC community are gratefully acknowledged. Presented in part at the 29 th Meeting of the European Association of the Study of Diabetes, Istanbul, Turkey, September 1993.

\section{References}

1. Bolli GB (1989) The pharmacokinetic basis of insulin therapy. Diab Res Clin Pract 6:S3-S16

2. Bolli G, Dimitriadis G, Pehling Get al. (1984) Abnormal glucose counterregulation after subcutaneous insulin in insulindependent diabetes mellitus. N Engl J Med 310: 1706-1711

3. Binder C, Lauritzen T, Faber O, Pramming S (1984) Insulin pharmakokinetics. Diabetes Care 7: 188-199

4. Dimitriadis G, Gerich J (1985) Importance of timing of preprandial subcutaneous insulin administration in the management of diabetes mellitus. Diabetes Care 6:374-377

5. Brange J, Ribel U, Hansen J et al. (1988) Monomeric insulins obtained by protein engineering and their medical implications. Nature (Lond) 333: 679-682

6. Brange J, Owens D, Kang S, Volund A (1990) Monomeric insulins and their experimental and clinical implications. Diabetes Care 13: 923-954

7. Frank BH, Brems DN, Chance RE, Di Marchi RD, Shields JE (1991) Manipulation of proline in the B-chain produces monomeric insulins. Diabetes 40 [Suppl 1]: $423 \mathrm{~A}$ (Abstract)

8. Howey DC, Bowsher RR, Brunelle RL, Woodworth JR (1994) [Lys (B28), Pro (B29)]-Human Insulin. A rapidly absorbed analogue of human insulin. Diabetes 43: 396-402

9. Ter Braak EW, Bianchi R, Erkelens DW (1993) Faster, shorter and more profound action of Lys(B28), Pro(B29) human insulin analogue compared to regular insulin irrespective of the injection site. Diabetes 42 [Suppl 1]: 207 A (Abstract)

10. Slieker LJ, Sundell K (1991) Modifications in the 28-29 position of the insulin B-chain alter binding to the IGF-I receptor with minimal effect on insulin receptor binding. Diabetes 40 [Suppl 1]: 168 A (Abstract)

11. Woodworth JR, Bowsher RR, Howey DC, Rowe HM, Ferguson AL (1992) Pharmacokinetic and pharmacodynamic comparison of [Lys B28, Pro B29] human insulin to Humulin R.Pharm Res 9 [Suppl 10]:S292

12. Woodworth J, Howey D, Bowsher R, Lutz S, Santa P, Brady P (1993) [Lys(B28), Pro(B29)] Human insulin: dose-ranging vs Humulin R. Diabetes 42 [Suppl 1]: 54 A (Abstract)

13. Tuominen JA, Karonen S-L, Koivisto VA (1993) Hypoglycemic effect of short-acting insulin analogue during exercise in type 1 diabetes. Diabetologia 36 [Suppl 1]:A156 (Abstract)

14. Howey DC, Rowe H, Brunelle R, Downing-Shelton J (1993) [Lys(B28), Pro(B29)] Human insulin: effect of injection time on glucose control. Diabetes 42 [Suppl 1]: $80 \mathrm{~A}$ (Abstract)

15. Trautmann ME, Attanasio A, Schulze-Schleppinghoff $B$, Stiller R, Niederreiter B, Haslbeck M (1993) Blood sugar control during treatment with an insulin analogue. Diabetologia 36 [Suppl 1]:A155 (Abstract)

16. Ewing DJ, Clarke BF (1982) Diagnosis and management of diabetic autonomic neuropathy. BMJ 285: 916-918

17. De Feo P, Perriello G, Ventura MM et al. (1986) Studies on overnight insulin requirements and metabolic clearance rate of insulin in normal and diabetic man: relevance to the pathogenesis of the dawn phenomenon. Diabetologia 29: $475-480$ 
18. McGuire E, Helderman J, Tobin R, Andres R, Berman M (1976) Effects of arterial versus venous sampling on analysis of glucose kinetics in man. J Appl Physiol 41: 565-573

19. Mitrakou A, Ryan C, Veneman T et al. (1991) Hierarchy of glycemic thresholds for counterregulatory hormone secretion, symptoms, and cerebral dysfunction. Am J Physiol 260:E67-E74

20. Schwartz N, Clutter W, Shah S, Cryer P (1987) Glycemic thresholds for activation of glucose counterregulatory systems are higher than the thresholds for symptoms. J Clin Invest 79: 777-781

21. Fanelli C, De Feo P, Porcellati F et al. (1992) Adrenergic mechanisms contribute to the late phase of hypoglycemic glucose counterregulation in humans by stimulating lipolysis. J Clin Invest 89: 2005-2013

22. Rizza R, Cryer P, Gerich J (1979) Role of glucagon, catecholamines, and growth hormone in human glucose counterregulation: effects of somatostatin and combined $\alpha$ - and $\beta$ adrenergic blockade on plasma glucose recovery and glucose flux rates after insulin-induced hypoglycemia. J Clin Invest 64: 62-71

23. Lowry O, Passonneau J (1972) Typical fluorimetric procedures for metabolite assays. In: Lowry O, Passonneau J (eds) A flexible system for enzymatic analysis. Academic Press, New York, pp 89-92

24. De Bodo R, Steele R, Altzuler A, Dunn A, Bishop J (1963) On the hormonal regulation of carbohydrate metabolism: studies with ${ }^{14} \mathrm{C}$ glucose. Recent Prog Horm Res 19: 445-448
25. Miles J, Haymond M, Gerich J (1982) Effects of free fatty acids, insulin, glucagon, and adrenaline on ketone body production in humans. In: Metabolic acidosis. Ciba Foundation 87, Pitman Books, London pp 192-213

26. Zar J (1984) Biostatistical analysis. Englewood Cliffs, Prentice Hall

27. Grottesman I, Mandarino L, Gerich J (1984) Use of glucose uptake and glucose clearance for the evaluation of insulin action in vivo. Diabetes 33: 184-191

28. Yki-Jarvinen H, Koivisto V (1986) Natural course of insulin resistance in type 1 diabetes. $N$ Engl J Med 315: 224-230

29. Bolli GB, Gottesman I, Campbell P, Haymond M, Cryer P, Gerich J (1984) Glucose counterregulation and waning of insulin in the Somogyi phenomenon (post-hypoglycemic hyperglycemia). N Engl J Med 311: 1214-1219

30. Bolli GB, Perriello G, Fanelli C, De Feo P (1993) Nocturnal blood glucose control in type 1 diabetes mellitus. Diabetes Care 16 [Suppl 3]: 71-89

31. Bruce D, Chisolm D, Storlien L, Kraegen E (1988) Physiological importance of deficiency in early prandial insulin secretion in non-insulin-dependent diabetes. Diabetes 37: 736744

32. Vignati L, Anderson J, Brunelle R (1994) Efficacy of Lys(B28), Pro(B29) human insulin in a one year global randomized clinical trial. Diabetes 43 [Suppl 1]: Abstract (in press) 